\title{
Prophylactic treatment of chronic renal disease in patients undergoing peritoneal dialysis and colonized by Staphylococcus aureus: a systematic review and meta- analysis
}

Cibele Grothe ${ }^{1 *}$, Mônica Taminato', Angélica Belasco ${ }^{1}$, Ricardo Sesso² and Dulce Barbosa ${ }^{1}$

\begin{abstract}
Background: This study was performed to evaluate the clinical effectiveness of alternative strategies for the prevention and treatment of patients with chronic kidney disease undergoing peritoneal dialysis and colonized by Staphylococcus aureus.

Methods: A systematic review and meta-analysis were performed. The literature search involved the following databases: the Cochrane Controlled Trials Register, Embase, LILACS, CINAHL, SciELO, and PubMed/Medline. The descriptors were "Staphylococcus aureus," "MRSA," "MSSA," "treatment," "decolonization," "nasal carrier," "colonization," "chronic kidney disease," "dialysis," and "peritoneal dialysis." Randomized controlled trials that exhibited agreement among reviewers as shown by a kappa value of $>0.80$ were included in the study; methodological quality was evaluated using the STROBE statement. Patients who received various antibiotic treatments (antibiotic group) or topical mupirocin (mupirocin group) were compared with those who received either no treatment or placebo (control group). Patients in the antibiotic group were also compared with those in the mupirocin group.

Results: In total, nine studies involving 839 patients were included in the analysis, 187 (22.3\%) of whom were nasal carriers of S. aureus. The probability of S. aureus infection at the catheter site for peritoneal dialysis was $74 \%$ lower in the mupirocin than control group (odds ratio [OR], 0.26; $95 \%$ confidence interval [CI], 0.14-0.46; $p<0$. 001), $56 \%$ lower in the antibiotic than control group $(\mathrm{OR}, 0.44 ; 95 \% \mathrm{Cl}, 0.19-0.99 ; p=0.048)$, and $52 \%$ lower in the mupirocin than antibiotic group $(\mathrm{OR}, 0.48 ; 95 \% \mathrm{Cl}, 0.21-1.10 ; p=0.084)$. The difference in the probability of S. aureus peritonitis in patients undergoing peritoneal dialysis was not statistically significant among the three groups. Conclusions: Mupirocin and topical antibiotics were effective for reduction of S. aureus catheter site infection in patients undergoing peritoneal dialysis when compared with no treatment or placebo. However, evidence was insufficient to identify the optimal agent, route, or duration of antibiotics to treat peritonitis.
\end{abstract}

Keywords: Staphylococcus aureus, Colonization, Infection, Peritoneal dialysis, Treatment

\footnotetext{
*Correspondence: cibelegrothe@hotmail.com

'Paulista School of Nursing, Federal University of São Paulo - EPE/UNIFESP, R.

Napoleão de Barros 754, São Paulo 04024-002, Brazil

Full list of author information is available at the end of the article
} 


\section{Background}

Peritoneal dialysis (PD) is an effective form of renal replacement therapy in patients with end-stage chronic renal failure. Despite recent improvements in connection technology, the development of skin infection at the catheter exit site and peritonitis remains a major cause of morbidity, hospitalization, catheter removal, termination of PD with permanent transfer to hemodialysis, and even death [1].

In 2005, the International Society for Peritoneal Dialysis determined that the peritonitis rate should be fewer than 0.67 episodes per patient per year [2], and in 2011 recommended that a rate of fewer than 0.36 episodes per year should be achieved by most programs [3]. However, rates of 0.63 to 1.66 episodes of peritonitis per patient per year and a catheter exit site infection rate of 0.72 episodes per year at risk have been reported $[4,5]$.

Worldwide, gram-positive cocci such as Staphylococcus epidermidis, coagulase-negative Staphylococcus, and $S$. aureus are the most frequent etiological agents in peritonitis associated with PD [2]. According Barreti et al. [6] the main causative agent of peritonitis in the world is coagulase-negative Staphylococcus however $S$. aureus is associated with the most severe episodes and increased risks of hospitalization, death, and catheter removal [7]. A rate of $S$. aureus peritonitis of 0.12 episodes per patient per year has been reported [4].

Approximately $20 \%$ of healthy people are chronic carriers of S. aureus, $30 \%$ are intermittent carriers, and $50 \%$ are not susceptible to carriage for unknown reasons [8]. An estimated 2 million individuals in the Netherlands are chronic carriers of $S$. aureus based on the prevalence rate in that country. In the United States, an estimated 53 million people are chronic carriers of $S$. aureus [8]. Aktaş et al. [9] demonstrated a clear association between $S$. aureus carriage and $S$. aureus infection in patients undergoing PD. Twenty-three genotypes were established for the 28 isolates, demonstrating high clonal heterogenecity. Six clinical isolates from four patients undergoing hemodialysis and four clinical isolates from two patients undergoing PD were molecularly evaluated to compare isolates obtained from infection with the carriage isolates of the same patients. All but one of these clinical isolates were "indistinguishable/closely related" to the isolates obtained from the same patients as the carriage isolates.

Various antimicrobial agents have been used for prevention of infection associated with $S$. aureus nasal colonization and peritoneal catheter exit site infection in patients with renal insufficiency. Mupirocin is an antibiotic that has been used locally in the nasal cavity and skin to eradicate $S$. aureus colonization with good results. Research conducted at the Federal University of São Paulo demonstrated that the application of topical mupirocin at the catheter insertion site significantly diminished the risk of $S$. aureus colonization and infection [10]. However, the emergence of multiresistant strains to this drug should be considered, as shown in a study conducted in Spain. That study revealed strains with high levels of resistance to mupirocin that were associated with a methicillinresistant $S$. aureus (MRSA) pandemic [11].

In addition, systemic antibacterial agents such as ciprofloxacin, novobiocin, trimethoprim/sulfamethoxazole, and rifampicin have also been used to eradicate colonization by $S$. aureus in patients with chronic renal failure. Among these antibiotics, rifampicin has been the most studied drug for this purpose [12].

Collection of surveillance cultures can be used to control the spread of multidrug-resistant pathogens. Early detection of patients colonized with multidrug-resistant microorganisms can allow for effective establishment of measures to control cross transmission. Eradication of the $S$. aureus carrier state includes prevention of infection and transmission. Several eradication strategies have been evaluated, but studies differ significantly in their design.

To fill some gaps in this regard, we considered it important to conduct a systematic review to evaluate the clinical effectiveness of alternative strategies for the prevention and eradication of $S$. aureus carriage in patients undergoing PD.

\section{Methods}

This systematic review and meta-analysis followed the steps proposed by the Cochrane Collaboration [13] and was performed in accordance with the PRISMA guidelines statement for systematic review reporting [14]. The inclusion criterion was $S$. aureus colonization in patients with chronic kidney disease undergoing PD as the primary outcome. The exclusion criteria were nonrandomized studies, letters, editorials, and case reports; studies involving patients $<18$ years of age; evaluation of $S$. aureus infection treatment outcomes without evaluation of the effect of nasal colonization; and no specification of the therapy administered to the treatment group. The two interventions compared in this meta-analysis were prophylactic treatment/decolonization to control cross transmission and $S$. aureus infection (peritonitis and skin infection at the catheter insertion site) between treated and untreated patients undergoing PD.

The following characteristics of each study were extracted: study design; total numbers of patients receiving various antibiotic treatments (antibiotic group), mupirocin (mupirocin group), and placebo or control (control group) with corresponding rates of eradication; colonization by $S$. aureus; and peritonitis.

\section{Study identification strategy}

Relevant studies published from January 1989 to January 2014 were identified through a search of the following 
electronic databases: the Cochrane Library (including the Cochrane Controlled Trials Register), Embase, LILACS, SciELO, CINAHL, and Medline/PubMed. The principal descriptors used in the search were "Staphylococcus aureus," "MRSA," "MSSA," "treatment," "decolonization," "nasal carrier," "colonization," "chronic kidney disease," "dialysis," and "peritoneal dialysis."

\section{Study selection}

The studies were read by two independent reviewers (C.G. and M.T.) to ascertain whether they fulfilled the inclusion criteria. The reviewers were not blinded. Each reviewer evaluated the titles and abstracts of all identified studies and obtained complete photocopies of all relevant articles. In cases of doubt or disagreement, a third reviewer (D.A.B.) was solicited to issue an opinion regarding whether the study should or should not be included.

\section{Evaluation of methodological quality}

Methodological quality was defined as confidence that the study design and reporting were free of bias. Two independent reviewers used the recommendations of the Cochrane framework and the STROBE statement (STrengthening the Reporting of OBservational studies in Epidemiology). Based on the STROBE recommendations [13], studies included in the meta-analysis were divided into three categories: (A) $>80 \%$ compliance with the STROBE criteria, (B) $50 \%$ to $80 \%$ compliance with the STROBE criteria, and $(C)<50 \%$ compliance with the STROBE criteria (Table 1).

\section{Data extraction and statistical analysis}

The studies were initially stratified according to their design. Based on these results, they were subsequently stratified following the Cochrane methodology. Comprehensive Meta-Analysis software was used for statistical analysis. For dichotomous variables, the odds ratio (OR) with $95 \%$ confidence interval $(\mathrm{CI})$ was calculated using random-effects and fixed-effects models. The MantelHaenszel chi-squared test and the $\mathrm{I}^{2}$ test were used to calculate heterogeneity [15].

\section{Results}

The PRISMA flow chart in Fig. 1 summarizes the search process. Initially, 143 articles were identified in the PubMed/Medline database, 54 in SciELO, 32 in
Cochrane, 4 in LILACS, and 10 in Embase. Of the 243 total studies identified, 234 were excluded (36 were articles published and duplicated in different databases, 96 met the exclusion criteria, 82 did not present the principal result, 11 did not evaluate nasal colonization by $S$. aureus, 5 did not report data on population control, and 4 did not report the duration of follow-up).

Thus, nine studies were evaluated: a prospective double-blind randomized controlled trial [16] and eight randomized clinical trials [17-24]. All studies were evaluated and classified as having a low risk of bias and adequate methodological quality by the Cochrane referential [13]. Randomization of the studies included in this review was performed by a computer, and concealment of the allocation was adequate.

These studies involved a total of 839 individuals (420 patients in the intervention group and 419 in the control group). Of these 839 individuals, 187 (22.3\%) were nasal carriers of $S$. aureus (see Additional file 1).

Based on the STROBE recommendations [13], eight studies were placed in category A and one study was placed in category B. This meta-analysis did not include studies in category $\mathrm{C}(<50 \%$ compliance with the criteria established by STROBE) (Table 1).

Different interventions were evaluated, including nasal agents (calcium mupirocin ointment $2 \%$ [16, 22], nasal neomycin ointment $0.1 \%$ [22], and sodium fusidate [20]), topically applied antimicrobial agents in the catheter exit site (calcium mupirocin ointment $2 \%[17,21$, $23,24]$, gentamicin sulfate $0.1 \%$ [21], cefazolin + gentamicin [19], and sodium fusidate [20]), and orally administered antibiotics (rifampicin $600 \mathrm{mg}[18,23]$ and ofloxacin [20]) (Table 2).

Several therapies were compared to evaluate the infection prevention effectiveness at the exit of the PD catheter and peritonitis caused by S. aureus. Mupirocin was compared with no treatment or placebo in two studies $[16,17]$. Mupirocin was compared with gentamicin, rifampicin, and neomycin in four studies [21-24]. The antibiotics rifampicin, cefazolin + gentamicin, ofloxacin, and sodium fusidate were compared with placebo or no treatment in three studies [18-20].

The probability of skin infection at the PD catheter exit site caused by $S$. aureus was $74 \%$ lower in the mupirocin than control group (OR, 0.26; $95 \% \mathrm{CI}, 0.14-$ 0.46; $p<0.001$ ) (Fig. 2), $56 \%$ lower in the antibiotic than control group (OR, 0.44; $95 \% \mathrm{CI}, 0.19-0.99 ; p=0.048$ )

Table 1 Quality of clinical trials included in the present meta-analysis

\begin{tabular}{lllllll}
\hline Concealment of allocation & Blinded investigator & Blinded participant & Blinded assessor & Blind data analysis & Intention-to-treat & Lost to follow-up \\
\hline Adequate: 5 & Yes: 4 & Yes: 4 & Yes: 3 & Yes: 1 & Declared: 3 & Yes: 6 \\
Inadequate: 1 & No: 2 & No: 1 & No: 1 & No: 1 & Not declared: 6 & No: 0 \\
Obscure: 3 & Obscure: 3 & Obscure: 4 & Obscure: 5 & Obscure: 7 & Obscure: 3 \\
\hline
\end{tabular}




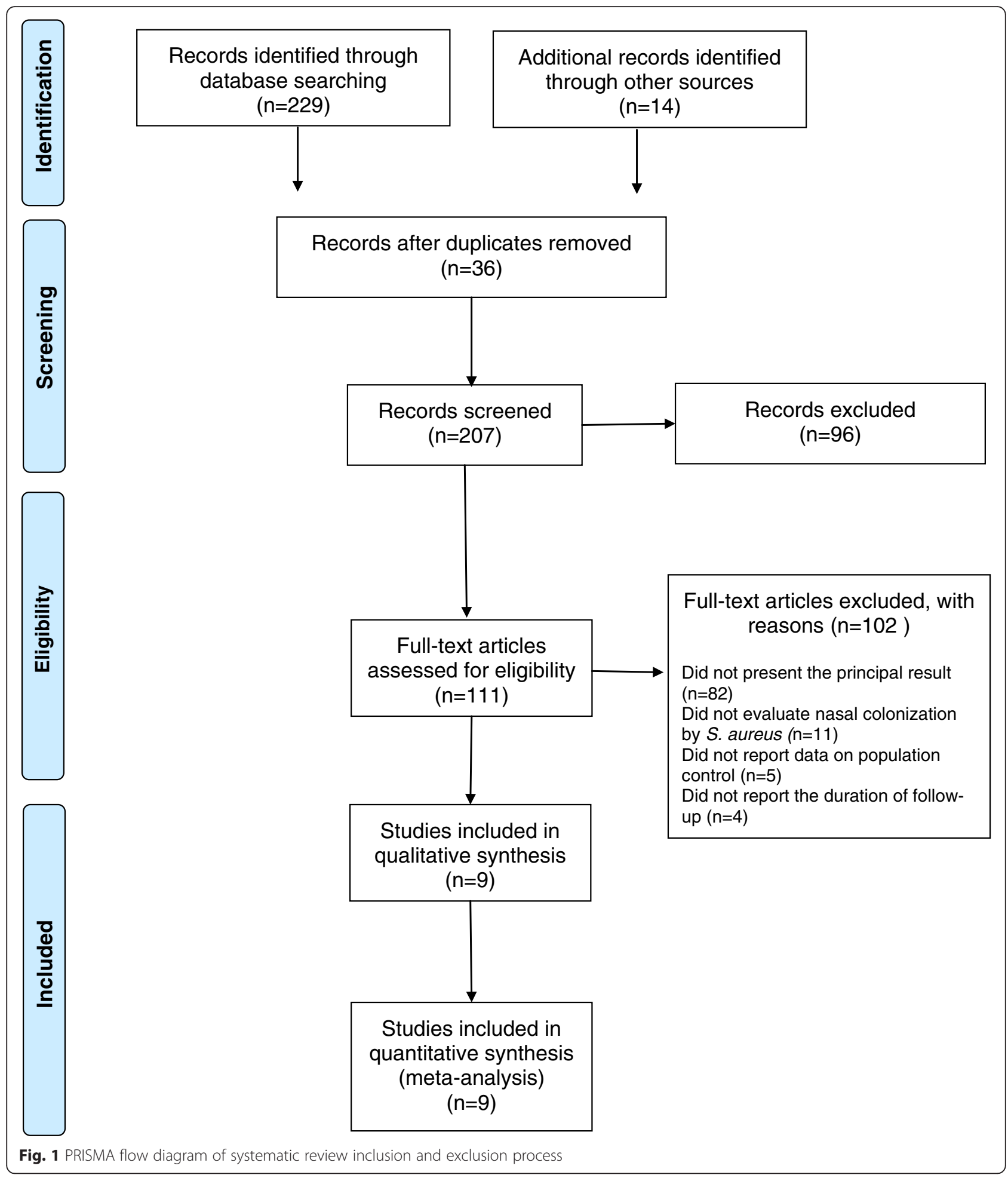

(Fig. 3), and $52 \%$ lower in the mupirocin than antibiotic group (OR, 0.48; $95 \%$ CI, 0.21-1.10; $p=0.084$ ) (Fig. 4).

The difference in the risk of peritonitis caused by $S$. aureus in patients undergoing PD was not significant among the three groups: mupirocin versus control group (OR, 0.68; 95 \% CI, 0.37-1.24; $p=0.20$ ) (Fig. 5), antibiotic versus control group (OR, 1.072; $95 \% \mathrm{CI}$, $0.43-2.69 ; p=0.88$ ) (Fig. 6), and mupirocin versus antibiotic group (OR, 0.74; $95 \% \mathrm{CI}, 0.18-3.05 ; p=0.67$ ) (Fig. 7).

Table 2 provides the following details: author, year of publication, study population, total number of included 
Table 2 Screening and treatment of chronic renal patients colonized with S. areus on peritoneal dialysis

\begin{tabular}{|c|c|c|c|c|c|c|c|c|c|c|c|c|c|c|c|}
\hline \multirow[t]{2}{*}{ Author } & \multirow[t]{2}{*}{ Year } & \multirow[t]{2}{*}{ Design } & \multicolumn{2}{|c|}{ Pacient (n.) } & \multicolumn{2}{|c|}{ NCSA (n./\%) } & \multicolumn{2}{|l|}{ Treatment } & \multicolumn{2}{|l|}{ Follow up } & \multirow[t]{2}{*}{ Erradication } & \multicolumn{2}{|l|}{$\underline{E S I}$} & \multicolumn{2}{|c|}{ Peritonitis } \\
\hline & & & $\begin{array}{l}\text { Treated } \\
\text { group }\end{array}$ & $\begin{array}{l}\text { Control } \\
\text { group }\end{array}$ & $\begin{array}{l}\text { Treated } \\
\text { group }\end{array}$ & $\begin{array}{l}\text { Control } \\
\text { group }\end{array}$ & Treated group & Control group & $\begin{array}{l}\text { Treated } \\
\text { group }\end{array}$ & $\begin{array}{l}\text { Control } \\
\text { group }\end{array}$ & & $\begin{array}{l}\text { Treated } \\
\text { group }\end{array}$ & $\begin{array}{l}\text { Control } \\
\text { group }\end{array}$ & $\begin{array}{l}\text { Treated } \\
\text { group }\end{array}$ & $\begin{array}{l}\text { Control } \\
\text { group }\end{array}$ \\
\hline $\begin{array}{l}\text { Mupirocin Study } \\
\text { Group [16] }\end{array}$ & 1996 & DCR & 134 & 133 & 18 & 24 & $\begin{array}{l}\text { Nasal mupirocin } 2 x / \text { day } \\
\text { for } 5 \text { days every } 4 \text { weeks }\end{array}$ & Placebo & 18 months & 18 months & $90 \%$ & 14 & 44 & 18 & 24 \\
\hline Wong [17] & 2003 & $\mathrm{ECR}$ & 73 & 81 & 16 & 14 & CESS mupirocin $1 \mathrm{x} / \mathrm{d}$ & No treatment & 5 months & 5 months & NT & 0 & 10 & 1 & 1 \\
\hline $\begin{array}{l}\text { Zimmerman } \\
\text { [18] }\end{array}$ & 1991 & ECR & 32 & 32 & 9 & 8 & $\begin{array}{l}\text { Oral rifampicin } 300 \mathrm{mg} \\
2 \mathrm{x} / \mathrm{d} \text { for } 5 \mathrm{~d} \text { every } \\
3 \text { months }\end{array}$ & No treatment & 10 months & 12 months & NT & 3 & 12 & 3 & 5 \\
\hline Lye [19] & 1994 & ECR & 41 & 105 & 3 & 6 & $\begin{array}{l}\text { Cefazolin + CESS } \\
\text { gentamicin }\end{array}$ & No treatment & 36 months & 36 months & NT & 2 & 4 & 2 & 0 \\
\hline Sesso [20] & 1998 & ECR & 9 & 13 & 5 & 5 & $\begin{array}{l}\text { Nasal and CESS sodium } \\
\text { fusidate }\end{array}$ & No treatment & 7,8 months & 7,8 months & $43 \%$ & 3 & 5 & 1 & 6 \\
\hline Sesso [20] & 1998 & ECR & & 13 & 5 & 5 & Oral Ofloxacin (dd) & No treatment & 7,8 months & 7,8 months & $40 \%$ & 2 & 5 & 4 & 6 \\
\hline Bernardini [21] & 2005 & $\mathrm{ECR}$ & 67 & 66 & 9 & 9 & $\begin{array}{l}\text { CESS mupirocin } 2 x / d \text { for } \\
5 d \text { every } 3 \text { months }\end{array}$ & $\begin{array}{l}\text { CESS gentamicin } 2 x / d \text { for } \\
5 d \text { every } 3 \text { months }\end{array}$ & 8 months & 8 months & $97 \%$ & 0 & 10 & 1 & 1 \\
\hline Fontán [22] & 1993 & $\mathrm{ECR}$ & 12 & 10 & 12 & 10 & Nasal mupirocina for $7 \mathrm{~d}$ & Nasal neomicin for $7 \mathrm{~d}$ & 9,5 months & 9,5 months & $100 \%$ & 1 & 1 & 0 & 1 \\
\hline Bernardini [23] & 1996 & $\mathrm{ECR}$ & 41 & 41 & 18 & 18 & CESS mupirocin daily & $\begin{array}{l}\text { Oral Rifampicin } 600 \mathrm{mg} \\
1 \times / \mathrm{d} \text { for } 5 \mathrm{~d} \text { every } \\
3 \text { months }\end{array}$ & months & 12 months & NT & 5 & 6 & 2 & 1 \\
\hline Cavdar [24] & 2004 & ECR & 18 & 18 & 3 & 0 & CESS mupirocin 3x/week & CESS mupirocin 1x/week & 6 months & 6 months & $83 \%$ & 0 & 1 & 0 & 1 \\
\hline
\end{tabular}

Note: $n$ number of patients, \% Percentage, NCSA nasal carrier of S. aureus, CESS catheter exit site skin, DBRCT Double blind randomized controlled trial, RCT randomized clinical trial, NT not tested, ESI Catheter Exit Site Infection, $3 x / w$ three times per week 


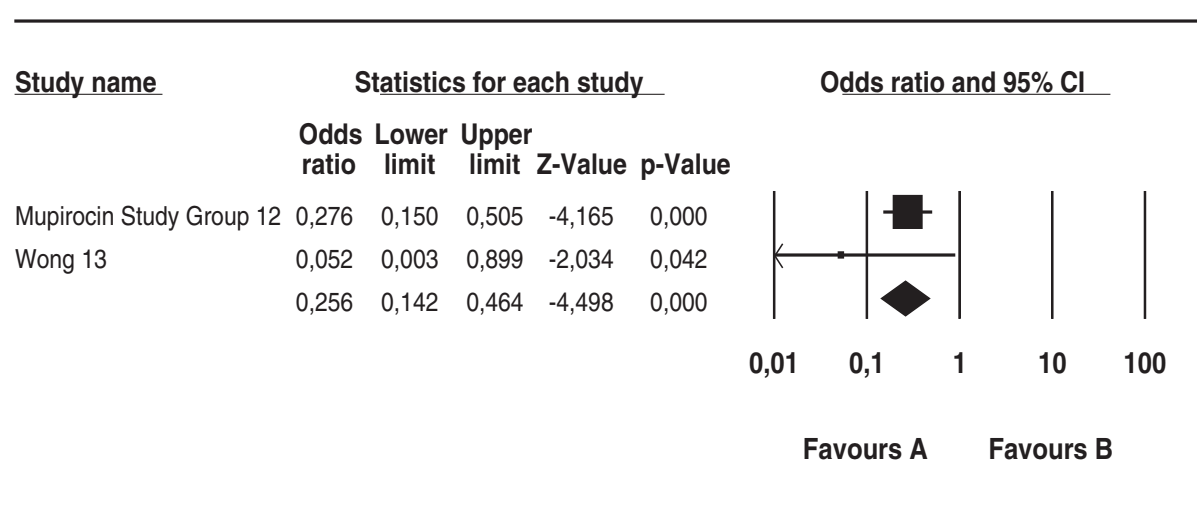

Fig. 2 Mupirocin treatment versus placebo or no treatment in patients on peritoneal dialysis colonized by S. aureus: Number of patients with CESI

patients, number of patients colonized with $S$. aureus at study entry, number of episodes of infection at the catheter exit site peritoneal dialysis; and number of episodes of peritonitis (number of episodes over total months in patient therapy).

\section{Discussion}

The rates of nasal $S$. aureus colonization, skin infection at the exit site of the PD catheter, and peritonitis were studied in this review. The review included 839 patients with chronic kidney disease undergoing PD, $22.3 \%$ of which were $S$. aureus nasal carriers.

Decolonization therapy may involve topical treatment by use of drugs at the catheter exit site or systemic antibacterials by oral administration of antibiotics. However, there is no evidence to indicate what type of treatment (topical or systemic) is most effective for such a procedure.

Topical treatments are widely used and evaluated, and the main antimicrobial agents tested include calcium mupirocin ointment $2 \%[16,17,21-24]$, sodium fusidate ointment $2 \%$ [20], cream gentamicin, neomycin sulfate [22], and cefazolin cream [19]. We found that topical mupirocin reduced the risk of $S$. aureus infection at the exit site of the PD catheter by $74 \%$ compared with the control group (placebo or no treatment) $(p<$ 0.001). Corroborating this result, it appears that mupirocin-based topical treatment is indicated by most guidelines of international health agencies, including the Centers for Disease Control and Prevention (CDC) [25] and World Health Organization (WHO) [26]. The CDC recommends the use of topical mupirocin alone in patients colonized only for a short period of time and for health care professionals [25]. Conversely, the WHO considers the use of mupirocin and/or chlorhexidine in patients with MRSA, but does not specify the indications, contraindications, or time of use [26]. Notably, for the National Institute of Clinical Excellence in the UK, the use of topical antimicrobials is not indicated in any case because there is no evidence that this practice may reduce health care associated infections (HAIs) either global or those caused by MRSA [27].

Another contraindication to mupirocin is bacterial resistance to this agent. In cases involving a mupirocin-resistant agent, the possibility of endogenous recolonization is high

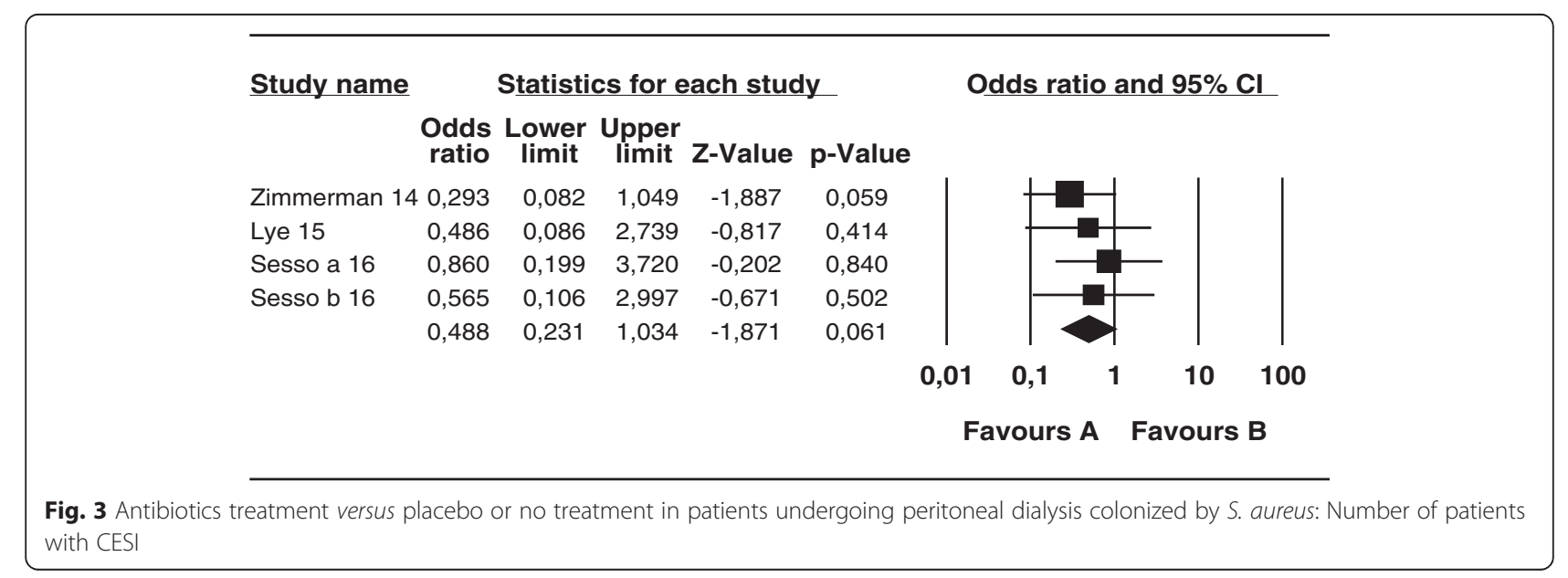




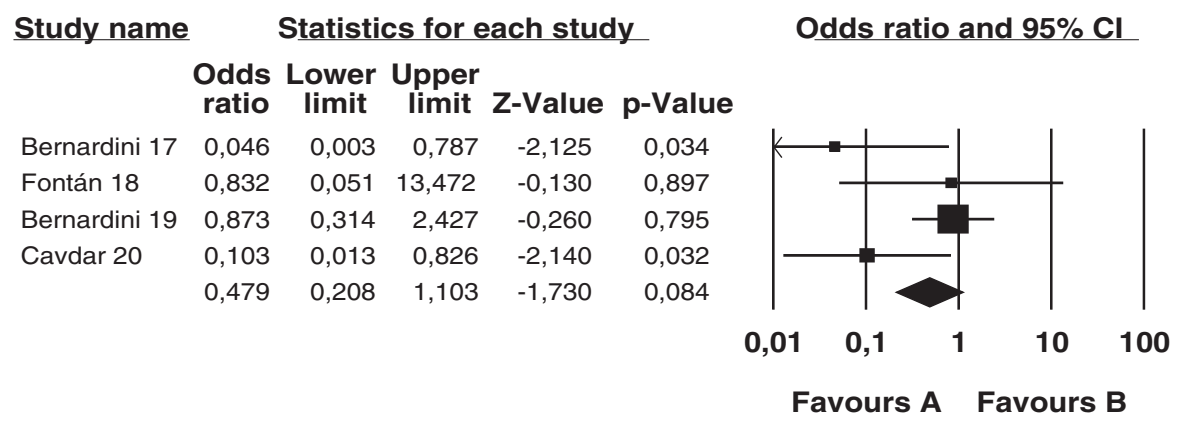

Fig. 4 Treatment with mupirocin vs. antibiotics in peritoneal dialysis patients colonized with S. aureus: Number of patients CESI

after 4 weeks of treatment [27]. However, resistance to mupirocin is still considered low. In this review, we found only one study that reported resistance to mupirocin in one isolated case.

Gentamicin and cefazolin were used together, and this combination provided effective results to reduce infection rates at the exit site of the PD catheter ( 0.23 vs 0.09 episode per patient per year; $p<0.005)$ and peritonitis $(0.33$ vs 0.10 episodes per patient per year; $p<0.005$ ) [19].

Fusidic acid was evaluated separately and exhibited statistically significant results $(p<0.01)$ [20] for $S$. aureus eradication in colonized patients. However, it is widely contraindicated as monotherapy for decolonization and is indicated only as a supportive treatment or enhancer to the use of systemic rifamycin. It did not show statistically significant results in reducing MRSA infections. Instead, it increased the emergence of bacterial resistance, which reinforces the idea of not using this drug alone for eradication of S. aureus in colonized patients [27].

Only one study compared the effectiveness of nasal neomycin sulfate ointment three times a day for 7 days with that of nasal mupirocin ointment daily for 7 days and reported that mupirocin is more effective than neomycin sulfate for elimination of $S$. aureus nasal colonization in patients undergoing continuous ambulatory PD [22].

In this meta-analysis, the antibiotic group exhibited a $56 \%$ lower risk of $S$. aureus infection at the PD catheter exit site compared with the control group $(p=0.048)$.

Systemic treatment alone for $S$. aureus eradication is not widely used; instead, systemic treatment is generally associated with a topical drug. This is mainly due to concerns about the emergence of strains resistant to antimicrobials [27]. The main antimicrobial agents for systemic use found in this study were rifamycin and ofloxacin $[18,20]$. In the main guidelines of international agencies (the WHO, CDC, and British Society for Antimicrobial Chemotherapy [24-26]), the systemic treatment recommendation for decolonization is that the therapeutic drug is chosen based on consultation with medical specialists in infectious diseases and epidemiologists at hospitals.

We found that patients treated with rifampicin showed a significant delay in the time to first infection associated with the PD catheter $(p<0.015)$ and significantly fewer infections related to the PD catheter $(p<0.001)$, but

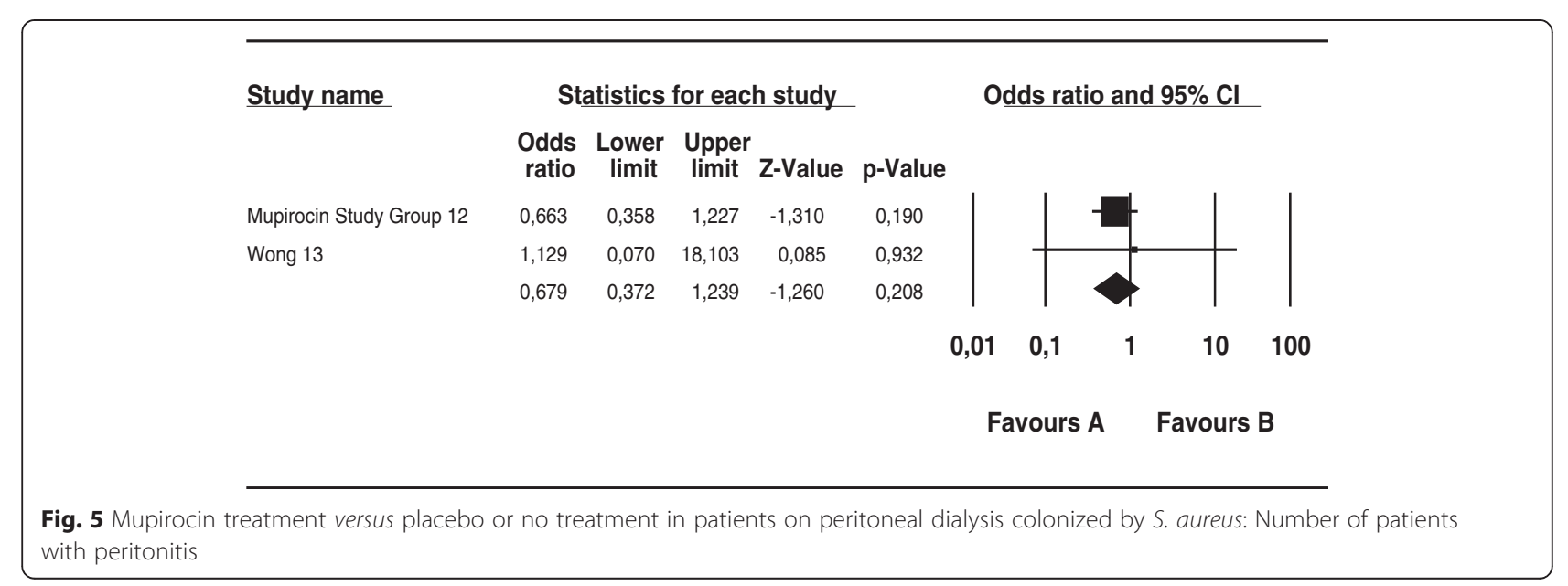




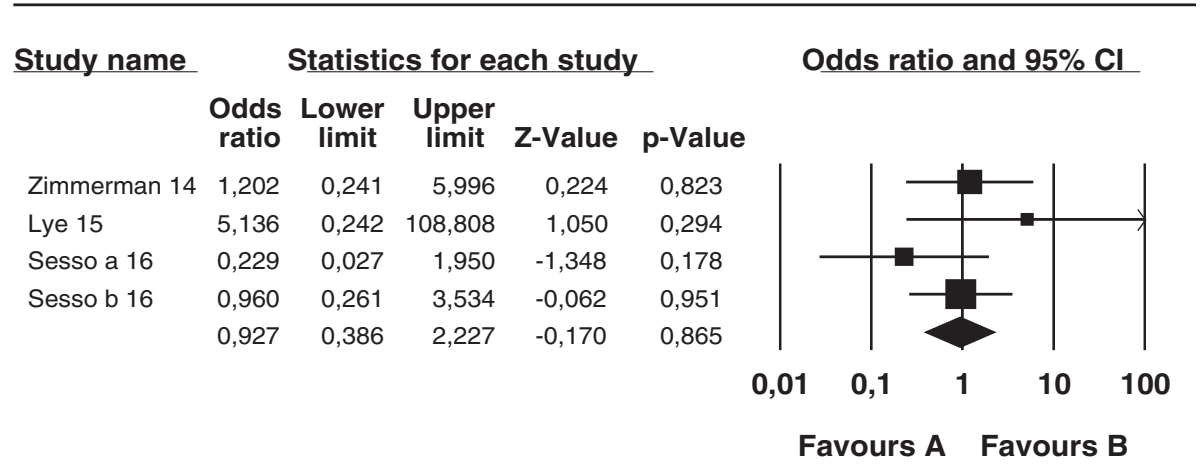

Fig. 6 Antibiotic treatment versus placebo or no treatment in patients on peritoneal dialysis colonized by S. aureus: Number of patients with peritonitis

rifampicin was associated with toxicity and side effects. Two studies reported treatment interruption due to toxicity in $6.6 \%$ to $12.0 \%$ of patients; however, no irreversible toxicity was observed, perhaps because of the short duration of treatment used in the studies, which may not have been long enough to cause significant clinical interactions [18, 23].

Another systemic medication used was oral ofloxacin, which was found in only one study and compared with the use of topical sodium fusidate ointment. Oral ofloxacin was less effective in the eradication of nasal colonization and reduction of infection at the PD catheter exit site, and both treatments showed no effect in reducing episodes of peritonitis [20].

This meta-analysis has shown that the use of topical antibiotics reduces the incidence of PD catheter exit site infection, but not the incidence of peritonitis. This may simply be a power problem (exit site infections being much more common than peritonitis, plus the relatively small numbers of patients involved), but raises the question about the relationships among carriage, infection, and peritonitis. It is likely that infection is introduced mainly at exchange via contamination of the catheter tip rather than tracking along the tunnel. A better technique might reduce the risk. Our findings are similar to those of the Cochrane Review by Strippoli et al. [15], who also concluded that nasal mupirocin reduces exit site and tunnel infections, but not peritonitis. The European Guidelines [28] state that the "use of mupirocin or gentamicin cream at the exit site is recommended to reduce exit site infections," but cites no evidence that this reduces peritonitis. Like the other guidelines, the authors had to extrapolate from reduction in exit site infections to reduction in peritonitis.

This review and meta-analysis had some limitations. The included studies had a short follow-up and did not allow for analysis of long-term treatment, which may have substantially different efficacy and safety than shown in the present results. Additionally, heterogeneity was present between the treatments applied, and it is not possible to conclude the best strategy for the use of these antibiotics. Moreover, local protocols and patient education interventions for the prevention of infection were not analyzed in this study.

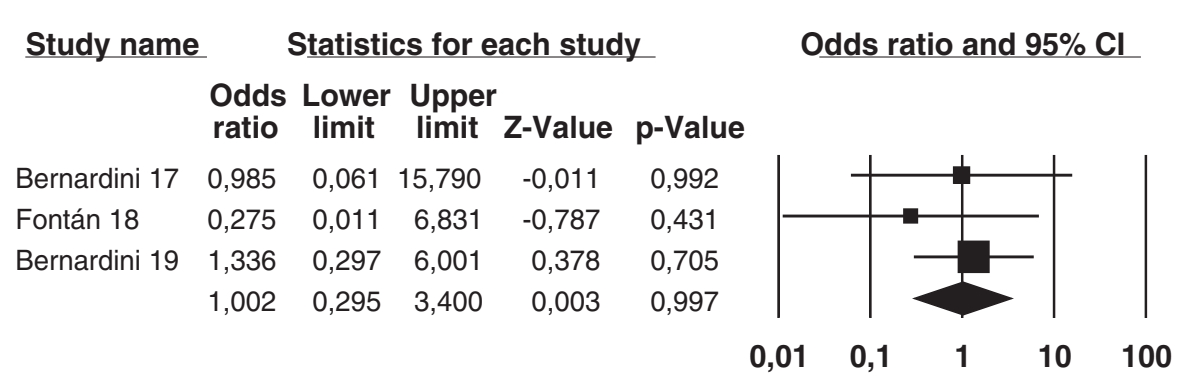

Favours A Favours B

Fig. 7 Treatment with mupirocin versus antibiotics in peritoneal dialysis patients colonized with S. aureus: Number of patients with peritonitis 
Because patients often become recolonized with $S$. aureus after receiving an initial treatment regimen, regular examinations with mupirocin application seems to be a reasonable option. Meticulous attention to infection control practices during insertion and access of the PD catheter is also of paramount importance in the prevention of $S$. aureus infection.

Future longitudinal studies need to define a mupirocin regimen that balances a reduction in the incidence of $S$. aureus infection with concerns about the emergence of mupirocin resistance.

\section{Conclusion}

Peritonitis is the main cause of the need to change PD to hemodialysis, which reduces patients' quality of life and increases costs to the national health system. Unfortunately, the current evidence base for the prevention of peritonitis is not supported. Nasal, oral, and local interventions reduce infections at the exit site of the PD catheter, but not peritonitis. However, this finding may be due to testing very small numbers of patients and for very short periods or because the incidence of peritonitis was low.

This meta-analysis supports the use of local antibiotics at the catheter exit site in patients undergoing PD. However, the available data are very limited, and more studies are needed to examine the clinical importance of antibiotics at the catheter exit site in patients undergoing PD.

\section{Additional file}

Additional file 1: PRISMA checklist. (DOC $63 \mathrm{~kb}$ )

\section{Abbreviations}

$\mathrm{Cl}$, confidence interval; MRSA, methicillin-resistant S. aureus; MSSA, methicillin-sensível S. aureus; OR, odds ratio; PD, peritoneal dialysis; PRISMA, guidelines statement for systematic review reporting; S. aureus, Staphylococcus aureus; STROBE, strengthening the reporting of observational studies in epidemiology

\section{Acknowledgements}

The authors acknowledge the São Paulo State Research Foundation (FAPESP) for its financial support of this study.

\section{Funding}

The authors received funding only from government agency FAPESP Fundação de Amparo à Pesquisa do Estado de São Paulo, a state research support foundation. No funding was received from commercial source.

\section{Availability of data and materials}

All data supporting these findings can be found in the following electronic databases: the Cochrane Library (including the Cochrane Controlled Trials Register), Embase, LILACS, SciELO, CINAHL, and Medline/PubMed.

\section{Authors' contributions}

CG was the principal researcher and participated in all steps of the study: development of the project, data collection, revision of the database, data analysis, and drafting and revision of the article. MT participated in development of the project, data analysis and article revision. $A B$ participated in revision of the database and revision of the article. RS helped to compose and revise the article. DAB coordinated and conceived of the study and participated in the project design, supervision of data collection, data analysis, and drafting and revision of the article. All of the authors read and approved the final version of the article.

\section{Author's information}

CG: Nurse, PhD, and postdoctoral student (EPE/UNIFESP)

MT: Nurse, MSc, PhD, and postdoctoral student (EPE/UNIFESP)

DF: Nurse, MSc, and PhD

MFPO: Nurse, MSc, and PhD

RS: Physician, MD, PhD, and Associate Professor (EPM/UNIFESP)

DB: Nurse, PhD, MSc, and Associate Professor Associado (EPE/UNIFESP)

\section{Competing interests}

The authors declare that they have no competing interests.

Ethics approval and consent to participate

Not applicable.

\section{Author details}

${ }^{1}$ Paulista School of Nursing, Federal University of São Paulo - EPE/UNIFESP, R. Napoleão de Barros 754, São Paulo 04024-002, Brazil. Division of Nephrology, Paulista School of Medicine, Federal University of São Paulo EPM/UNIFESP), R. Botucatu 740, São Paulo 04023-900, Brazil.

Received: 28 April 2015 Accepted: 21 June 2016

Published online: 15 August 2016

\section{References}

1. Pignatari A, Pfaller M, Hollis R, Sesso R, Leme I, Herwaldt L. Staphylococcus aureus colonization and infection in patients on continuous ambulatory peritoneal dialysis. J Clin Microbiol. 1990;28(9):1898-902.

2. Piraino B, Bailie GR, Bernardini J, Boeschoten E, Gupta A, Holmes C, ISPD Ad Hoc Advisory Committee, et al. Peritoneal dialysis-related infections recommendations: 2005 update. Perit Dial Int. 2005:25:107-31.

3. Piraino B, Bernardini J, Brown E, Figueiredo A, Johnson DW, Lye WC, et al. ISPD position statement on reducing the risks of peritoneal dialysis-related infections. Perit Dial Int. 2011;31:614-30.

4. Figueiredo AE, Figueiredo CEP, Meneghetti F, Lise GAP, Detofoli CC, Silva LB Peritonites em pacientes em diálise peritoneal: análise de um único centro brasileiro segundo a Sociedade Internacional de Diálise Peritoneal. J Bras Nefrol. 2013:35(3):214

5. Cleper R, Davidovits M, Kovalski Y, Samsonov D, Amir J, Krause I. Peritonitis in a pediatric dialysis unit: local profile and implications. Isr Med Assoc J. 2010;12:348-52.

6. Barretti $\mathrm{P}$, Bastos KA, Dominguez J, Caramori JC. Peritonitis in Latin America. Perit Dial Int. 2007;27:332-9.

7. Grothe C, Belasco AG, Bittencourt AR, Vianna LA, Sesso R, Barbosa DA. Incidence of bloodstream infection among patients on hemodialysis by central venous catheter. Rev Lat Am Enfermagem. 2010;18(1):73-80.

8. Becker K, Machka K, Stammer H, Peters G. Nasal carriage as a source of 404 Staphylococcus aureus bacteremia. Study Group. 2001;344(1):11-6.

9. Aktaş E, Pazarli O, Külah C, Cömert F, Külah E, Sümbüloğlu V. Determination of Staphylococcus aureus carriage in hemodialysis and peritoneal dialysis patients and evaluation of the clonal relationship between carriage and clinical isolates. Am J Infect Control. 2011;39:421-5.

10. Barbosa DA, Dalboni M, Leme I, Rabello T, Pignatari AC, Sesso R Staphylococcus aureus nasal carrier state in CAPD patients - a four years study. In: Mollby R, Flock Jl, Nord CE, Christensson B, editors. Staphylococci and Staphylococcal infection. New York: Gustav Fischer Verlag; 1994. p. 159-61.

11. Moore C, Dhaliwal J, Tong A, Eden S, Wigston C, Willey B, McGeer A. Risk factors for methicillin-resistant Staphylococcus aureus (MRSA) acquisition in roommate contacts of patients colonized or infected with MRSA in an acute-care hospital. Infect Control Hosp Epidemiol. 2008;29:600-6.

12. Zimmerman SW, Johnson CA. Rifampin use in peritoneal dialysis. Perit Dial Int. 1989;9(4):241-3.

13. Higgins JP, Green S, editors. Cochrane handbook for systematic reviews of intervention. Chichester (UK): John Wiley \& Sons; 2005. 
14. Moher D, Liberati A, Tetzlaff J, Altman DG, Group P. Preferred reporting itms for systematic reviews and meta-analyses: the PRISMA statement. J Clin Epidemiol. 2009;62:1006-12.

15. Rev Man Analyses (RevMan) [computer software] Version 1.0 for Windows, in Review Manager 5.1. Oxford: The Cochrane Collaboration; 2005.

16. The Mupirocin Study Group. Nasal mupirocin prevents Staphylococcus aureus exit-site infection during peri- toneal dialysis. J Am Soc Nephrol. 1996;7:2403-8.

17. Wong SSH, Chu K-H, Cheuk A, Tsang WK, Fung SKS, Chan HWH, et al. Prophylaxis against Gram-positive organisms causing exit-site infection and peritonitis in continuous ambulatory peritoneal dialysis patients by applying mupirocin ointment at the catheter exit site. Perit Dial Int. 2003;23 Suppl 2:S153-8.

18. Zimmerman S, Ahrens E, Johnson C, Craig W, Leggett J, O'Brien M, et al. Randomized controlled trial of pro- phylactic rifampin for peritoneal dialysis-related in- fections. Am J Kidney Dis. 1991;18(2):225-31.

19. Lye WC, Leong SO, van der Straaten J, Lee EJ. Staphylococcus aureus CAPD-related infections are associated with nasal carriage. Adv Perit Dial. 1994:10:163-5.

20. Sesso R, Barbosa D, Leme I, Sader H, Canziani ME, Manfredi S, et al. Staphylococcus aureus prophylaxis in hemodialysis patients using central venous catheter: effect of mupirocin ointment. J Am Soc Nephrol. 1998;9(6): 1085-92.

21. Bernardini J, Bender F, Florio T, Sloand J, Palmmontalbano L, Fried L, et al. Randomized, double-blind trial of antibiotic exit site cream for prevention of exit site infection in peritoneal dialysis patients. J Am Soc Nephrol. 2005;16:539-45.

22. Perez-Fontan M, Garcia-Falcon T, Rosales M, et al. Treatment of Staphylococcus aureus nasal carriers in continuous ambulatory peritoneal dialysis with mupirocin: long-term results. Am J Kid Dis. 1993;22:708-12.

23. Bernardini J, Piraino B, Holley J, Johnston JR, Lutes R. A randomized trial of Staphylococcus aureus prophylaxis in peritoneal dialysis patients: mupirocin calcium ointment $2 \%$ applied to the exit site versus cyclic oral rifampin. Am J Kidney Dis. 1996;27:695-700.

24. Cavdar C, Zeybel M, Atay T, Sifil A, Sanlidag C, Gulay Z, et al. The effects of once- or thrice-weekly mupirocin application on mupirocin resistance in patients on continuous ambulatory peritoneal dialysis - first 6 months' experience. Adv Perit Dial. 2004;20:62-6.

25. Coia JE, Duckworth GJ, Edwards DI, Farrington M, Fry C, Humphreys H, Mallaghan, Tucker DR. Guidelines for the control and prevention of meticillin-resistant Staphylococcus aureus (MRSA) in healthcare facilities. J Hosp Infect. 2006;63 Suppl 1:S1-44.

26. Gemmell CG, Edwards DI, Fraise AP, Gould FK, Ridgway GL, Warren RE. Guidelines for the prophylaxis and treatment of methicillin-resistant Staphylococcus aureus (MRSA) infections in the UK. J Antimicrob Chemotherapy. 2006. [Acesso 23 Mar 2010]. Disponivel em: http://jac. oxfordjournals.org/content/57/4/589.short.

27. National Institute for Health and Clinical Excellence. Surgical site infection: prevention and treatment of surgical site infection. London (UK): NIHCE; 2008.

28. Krediet RT. European best practice guidelines on peritoneal dialysis. Nephrol Dial Transplant. 2005;20(Suppl 9):ix8-ix12.

\section{Submit your next manuscript to BioMed Central and we will help you at every step:}

- We accept pre-submission inquiries

- Our selector tool helps you to find the most relevant journal

- We provide round the clock customer support

- Convenient online submission

- Thorough peer review

- Inclusion in PubMed and all major indexing services

- Maximum visibility for your research

Submit your manuscript at www.biomedcentral.com/submit

) Biomed Central 